\section{Methionine Requirements of Rats in Various Body Weights}

\author{
Teru Ishibashi and Masao Kametaka
}

Department of Agricultural Chemistry, Faculty of Agriculture, The University of Tokyo, Tokyo 113

Received April 14, 1977

There is considerable information available regarding the methionine requirement of rats, but findings ${ }^{1 \sim 7}$ are rather variable as shown in Fig. 1.

These variations may be because of differences in the body weights, strains, physiological or nutritional status of animals and the parameters used, especially the body weights of animals. The rate of synthesis being relative to that of catabolism or replacement of body protein will shift continuously during the period of growth of animal. In fact, the authors observed that the lysine requirement of rats as percentage of the diet decreased with increasing of body weight exponentially, and the regression equation was $Y=1.03-0.58$ $\log X$, where $Y=$ requirement $\%$ of the diet and $X=$ body weight g. $^{8}$

In contrast to the above observation, the methionine requirement of chicks decreased with increasing body weight not exponentially but linearly (unpublished data). Thus, the objective of this report was to make clear whether the methionine requirement decrease with increasing body weight linearly or exponentially by using the oxidation technique and the feeding tests. The requirements of methionine were determined at 4 different stages of growth in rats.

For each experiment, male rats of Wistar strain were fed a stock diet for 1 week. Then the rats were assigned at random to 6 groups of 4 rats each on the experimental diets. The diets with 6 levels of methionine were prepared, ranging in methionine content from 0.125 to $1.00 \%$ of the diet. The composition of amino acid mixture and other components of diets and the care of animals were the same as in the previous report. ${ }^{8)}$ In all experiments, feeds and water were supplied ad libitum for 7 days. At the end of the feeding test, 3 rats from each dietary group were used to examine methionine oxidation rate as an index for determining requirement. Each rat was injected with $0.38 \mu \mathrm{Ci}$ of L-methionine-methyl ${ }^{14} \mathrm{C}$ in $0.10 \mathrm{ml}$ of $0.9 \%$ saline solution. Immediately following injection, each rat was placed in a respiratory chamber and expired carbon dioxide was collected for $18 \mathrm{hr}$ as described in the previous report. ${ }^{8)}$

The average daily gain of body weight and the recovery $\%$ of ${ }^{14} \mathrm{C}$ in the expired carbon dioxide of rats

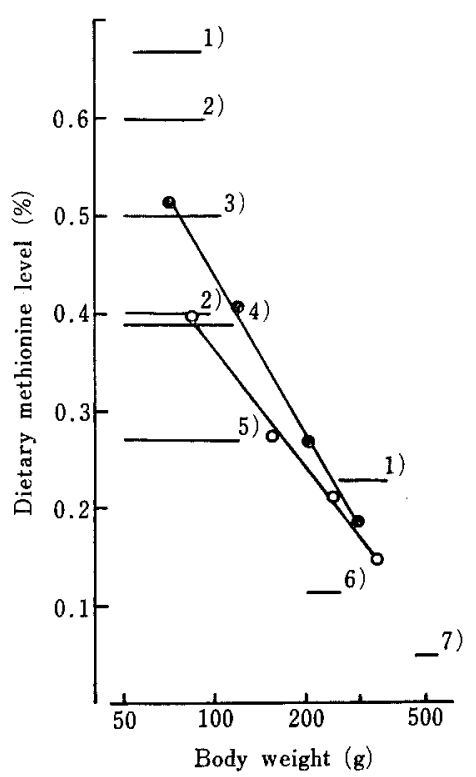

FIG. 1. Requirements of Methionine of Rats in Various Body Weights Obtained by Feeding Test ( $)$ and Isotope Technique $(O)$ and by Others by Various Methods (-). $\left.{ }^{1 \sim 7}\right)$

$$
\begin{aligned}
& Y=0.99-0.54 \log X \\
& Y=0.71-0.34 \log X
\end{aligned}
$$

(1) $Y=$ requirement $(\%)$ and $X=$ average body weight during feeding test.

(2) $Y=$ requirement $(\%)$ and $X=$ body weight at injection.

weighing 40 to $50 \mathrm{~g}$ against the dietary methionine level are shown in Fig. 2. The methionine requirement measured by the optimum weight gain was estimated to be $0.52 \%$ of the diet by the least squares method.

At levels below a certain dietary methionine level, the recovery $\%$ of ${ }^{14} \mathrm{C}$ in the respiratory $\mathrm{CO}_{2}$ was low and remained relatively constant with increasing methionine levels. Above this methionine level, the recovery \% of ${ }^{14} \mathrm{C}$ increased linearly with greater content. The requirement for methionine was estimated to be $0.46 \%$ in the diet by the least squares method. The requirement obtained from the oxidation technique was somewhat lower than that estimated from the average daily gain data. Brookes et al..$^{9}$ observed a similar phenomenon when comparing estimates of lysine requirements based on the oxidation rate with those based on the average daily gain of the rats weighing 50 to $60 \mathrm{~g}$. In these experiments, it should be noted that whereas the feeding test covered a long day period, the oxidation test was conducted only during the last 1 day after the feeding test. As shown in the previous report, ${ }^{8}$ within the feeding test, with changing body weights and rates of growth, requirements are changing with time.

When $0.25 \%$ of cystine was added to the 0.25 and 


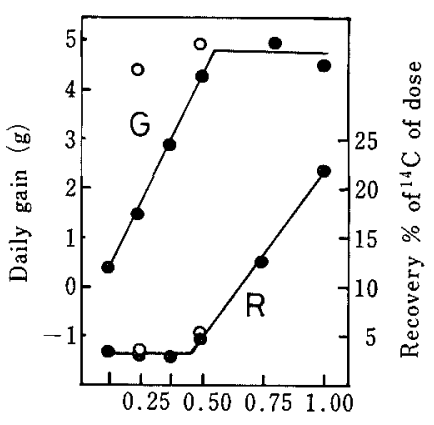

Dietary methionine level $(\%)$

FIG. 2. Daily Gain of Body Weight (G) and Percentage of ${ }^{14} \mathrm{C}$. Recovered in Respiratory $\mathrm{CO}_{2}(\mathrm{R})$ of Rats Weighing $50 \mathrm{~g}$ at Starting Experiment Fed Graded Level of Methionine without Cystine (1) or with $0.25 \%$ Cystine Diet $(O)$ for 7 days.

$0.50 \%$ methionine diet (open circles in Fig. 2), the optimal gain was obtained at $0.25 \%$ of methionine. However, no effect of presence of cystine on the recovery $\%$ of ${ }^{14} \mathrm{C}$ in the respiratory $\mathrm{CO}_{2}$ was observed in contrast to the feeding test. These observations suggest that the half of methionine needed for the optimal growth is replaceable by cystine, but cystine derived from methionine is metabolized regardless of dietary level of cystine. Since most of methionine is converted to cystine in the body, methionine may be metabolized in the other pool in which dietary cystine is metabolized as the labeled tyrosine derived from phenylalanine was not by tyrosine added in excess. ${ }^{10)}$

The requirements of methionine determined at the other stages in the same way are summarized in Fig. 1.
From the above data, it is concluded that the requirements of methionine decreased exponentially with increasing body weight. The regression equations obtained are $Y=0.71-0.34 \log X$ by the oxidation technique, where $Y$ is the dietary methionine $\%$ in the diet and $X$ is the body weight (g) of rats gained optimal growth at the injected time, and $Y=0.99-0.54 \log X$ by the feeding test, where $Y$ is the dietary methionine level in the diet and $X$ is the mean of initial and final body weights $(\mathrm{g})$ of rats gained optimal growth during the feeding test.

\section{REFERENCES}

1) National Academy Science-National Research Council, NRC Publ Washington, D. C. (1971).

2) T. S. Aguilar, N. Benevenga and A. E. Harper, J. Nutr., 104, 761 (1974).

3) P. B. Rama Rao, V. C. Metta and B. C. Johnson, ibid., 69, 387 (1959).

4) R. W. Boggs, J. T. Rotruck and P. A. Damico, ibid., 105, 326 (1975).

5) Y. Miyazaki and S. Hayakawa, J. Jap. Soc., Food and Nutr., 17, 12 (1959).

6) A. K. Said and D. M. Hegsted, J. Nutr., 100, 1363 (1970).

7) A. Yoshida, Reports of the Research Committee of Essential Amino Acids, 52, 11 (1971).

8) T. Ishibashi and M. Kametaka, Agric. Biol. Chem., 41, 1727 (1977).

9) I. M. Brookes, F. N. Owens and U. S. Garrigus, J. Nutr., 102, 27 (1972).

10) R. Funabiki and M. Kandatsu, Nippon Nôgeikagaku Kaishi, 39, 307 (1965). 